\title{
Global and Local Optimization Method to Determine RoRo's Principle Particulars
}

\author{
Hasanudin ${ }^{1, a, *}$, Achmad Baidowi ${ }^{2, b}$ \\ ${ }^{1}$ Department of Naval Architecture, Institut Teknologi Sepuluh Nopember, Surabaya, Indonesia \\ ${ }^{2}$ Department of Marine Engineering, Institut Teknologi Sepuluh Nopember, Surabaya, Indonesia \\ a.hasanudinits@gmail.com,b.ahmadbai@gmail.com \\ *corresponding author
}

Keywords: Optimization, Global and Local, Principal particular

Abstract: The determination the principal particulars of RoRo in design stage has crucial influence to technical and economic performance. This Global and Local (GOLOC) optimization is able to provide optimum principal particulars. The global optimization is used to obtain optimum value of the global objective function and the local is used to find the local optimization value. GOLOC method requires two stages of optimization, the global optimization which produce one set of feasible principal particulars and the second stage is local optimization which use global optimization results as input. The local optimization is conducted to reduce the weakness of global results. There are 16 results of global optimization which satisfies all required constraints which resulted 10,000 trainings. The difference between maximum and minimum of global optimization result is $7.02 \%$ while the difference between minimum of global optimization and minimum objective function of local optimization result is $2.17 \%$. The GOLOC optimization able to improve optimization result without trapped in the one point of variable.

\section{Introduction}

RoRo Passenger (RoPax) is a ship that is needed for the outer island community, there is a big gap of development between advanced island and outer islands. This huge gap needs to be facilitated, one of the options is the Landing Craft Tank (LCT) vessel which has ability to conduct beaching or to dock on a beach without any jetty facility. The operational of this vessel has been banned due to the unavailability of enclosed spaces for passengers. In the other side RoPax can carry passengers, vehicles and goods. Vehicles and Goods are placed on the main deck and above the deck is used for passenger space [1] [2]. One of the solutions is to design a vessel which can accommodate the unique ability of LCT and a RoPax, the answer is to design LCT which able to carry Passenger, vehicle and goods. In the early design stage, the determination of principal particulars is very crucial which will affect the ship technical and economic performance [3].

In the design stage, an optimization process is a compulsory to find a solution between cost efficiency and technical requirements. There are at least two method types of optimization, the local and the global method. Global optimization methods can search for results in general optimum but 
not for the higher optimum. To find higher optimum requires more complex calculation and time consuming. The local optimization method can find the most optimal area but this method has the weakness which can be trapped on local optimum [4] [5] [6]. This paper offers a combination both of the method to overcome the weakness. This method named GOLOC optimization method.

The optimization methods in ship industry has been widely used, as an example in basic design [7], hydrodynamic design [8] and structural design [9]. Determining the exact size of the main vessel is important as it affects: power, propulsion, freeboard, and stability, Gross Tonnage (GT), Net Tonnage (NT), building costs and operating costs. Determination of the main size of this ship can be done by optimization method [10]. The application of GOLOC optimization methods may provide optimum global and local optimum main particulars.

\section{Literature Review}

Optimization method is numerical method to obtain optimum value (maximize or minimize). Optimum value based on Objective Function which called variable. Often, in calculation there are some limitation which called constraints which must be equal, exceeding or some values in calculation are given which will not change, this value called perimeter. And there are values which not changed called constant. Statement of an optimization problem can be written as [11].

Subject to the constraints:

$$
\text { Find } X\left\{\begin{array}{c}
x_{1} \\
x_{2} \\
\vdots \\
x_{n}
\end{array}\right\} \text { which minimizes } f(X)
$$

$$
\begin{gathered}
g_{j}(X) \leq 0, j=1,2, \ldots \ldots, m \\
l_{j}(X)=0, j=1,2, \ldots ., p
\end{gathered}
$$

Artificial Neural Network (ANN) is one of global optimization method which replicate how human brain works. ANN has been used widely in many engineering applications, and one of the application is in vessel principal particulars determination [12] [13]. The determination of principal particulars conducted by obtaining initial principal particulars and this initial data will be varied based on $\mathrm{L}, \mathrm{B}, \mathrm{H}$ and $\mathrm{T}$, these variations will create combination which included in technical calculation. The result of the combination must satisfy constraints which has been set. The ANN scheme for principal optimization can be shown in Fig.1 [14].

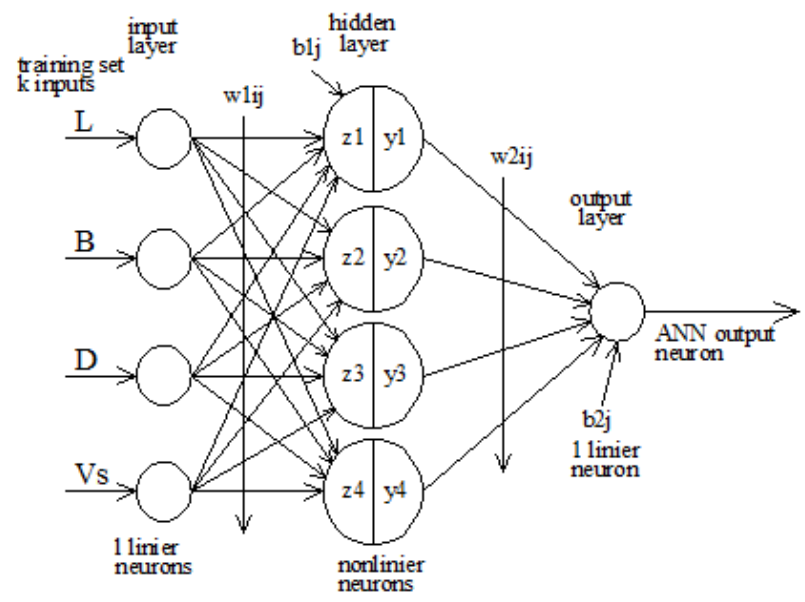

Figure 1: Artificial Neural Network (ANN) for Optimization. 


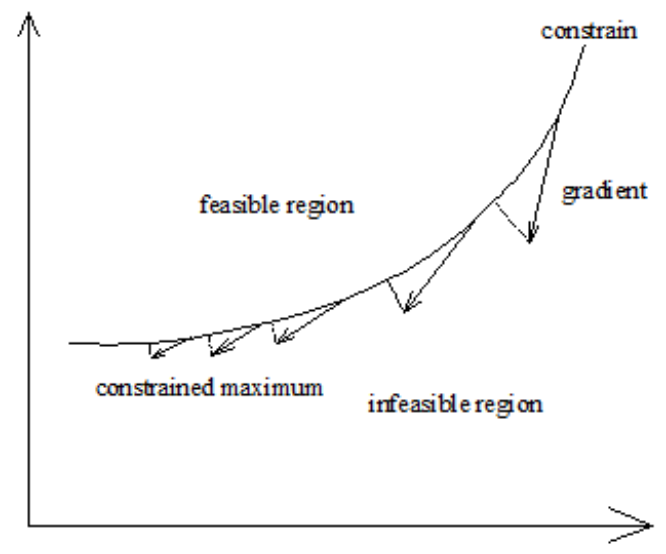

Figure 2: Generalized Reduced Gradient

Generalized Reduced Gradient (GRG) as shown by Fig.2 is one of the local optimization method. It is conducted when the initial value of mathematical model is defined. For two-particulars problem, the next step is the calculation of the right and the left side of equation. The maximum value will be taken when the Objective Function is to maximize the case while minimum value will be taken to minimize Objective Function. The calculation will be stopped when the gradient has reached zero. This method can be applied for $\mathrm{n}$ principle particulars problem where the tool is provided in Ms Excel. The application of this method has been conducted in principal particulars calculation of preliminary ship design stage [7].

Based in the Fig.3, it can be explained that GOLOC uses two stages optimization, global optimum and followed by local optimum. The optimized global optimization method uses ANN (Artificial Neural Network) method, this method is reliable because it imitates human intelligence while for the local optimization method uses GRG, which is very reliable to obtain optimum point in short time.

The results of global method optimization are obtained by varying the principal particulars of the vessel and producing a set of principal particular that meet the required constraints. The result of global optimization calculations taken as input in the local optimization which employs GRG method. The final result will be optimum both for global and local optimization.

\section{Literature Review}

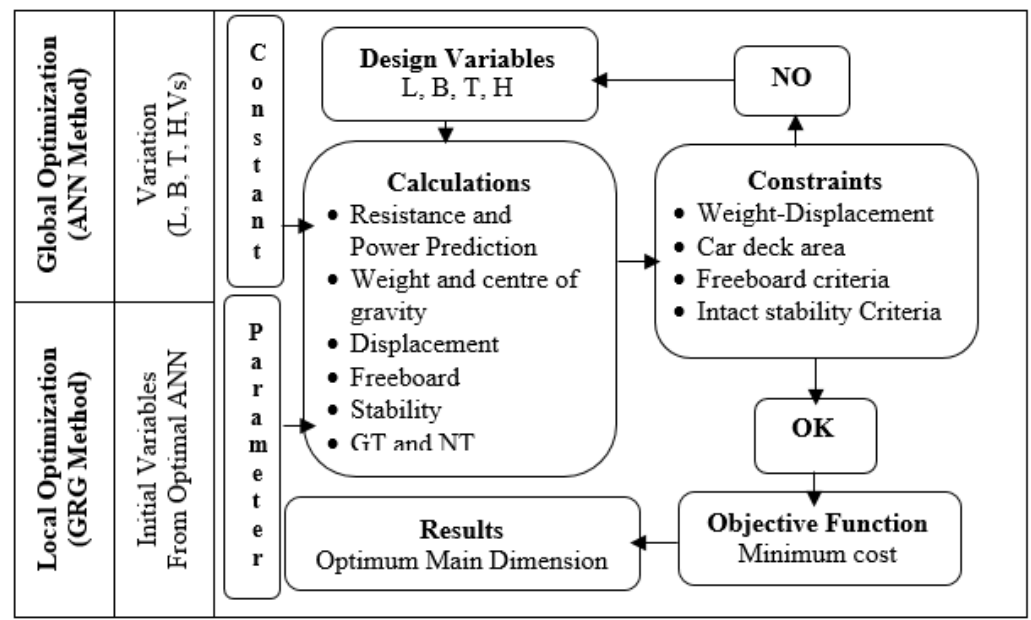

Figure 3: GOLOC Algorithm. 
In this paper, the case is to calculate the initial main particulars is taken from the existing vessel. The chosen variable is length $(\mathrm{L})$, breadth $(\mathrm{B})$, height $(\mathrm{H})$, and draft $(\mathrm{T})$. The objective function is to minimize the production and operational cost. The constraint is weight, displacement, GT, Freeboard and stability. The model of this optimization can be shown in Table 3 . The technical calculations are resistance and power prediction based Holtrop method [15], stability calculation uses manning method [16], stability criteria use IS code [17] the freeboard calculation uses International Load Line Convention [18], The GT and NT calculation uses ICTM [19], and the weight calculation uses Batram method [20]. The economical calculation is based on data which provided by shipyard who had been built the same RoPax.

The two-stage optimization started by global optimization using ANN and the second stage is local optimization using GRG. The ANN conducted by variation of 4 variables ( $\mathrm{L}, \mathrm{B}, \mathrm{H}$ and $\mathrm{T}$ ) as shown in Fig.1. The initial step of ANN is 2 variations of variable, the results is 24 or 16 training of ANN. If the 2 variations still unable to satisfies the Objective Function, the optimization will be continued to 4 variation which resulted 24 or 256 . This variation will be continued to 6,8 or 10 variations until the results satisfies the global optimization constraint. The variable input variation is conducted in the same distance based on the distance of upper limit and lower limit divided by variable variation. The modelling constructed in Visual Basic (VBA) of Ms Excel.

The local optimization or GRG is conducted in Ms. Excel. This optimization process is processed by using results of global optimization as inputs in local optimization. The procedure of this method is shows by Fig.2. It shows for one variable case, when initial values have been given, the variable will be variated into 2 variations. This variation values will be added and subtracted by certain interval of step. The next step is the variable is accounted in calculation and compared the results in the Objective Function. The Objective Function comparison is between initial Objective Function and two Objective Function resulted from the two steps of adding and subtracting the initial values. If the case is minimization, the selected Objective Function is the smallest values. This step will be stopped until the gradient of the function reached zero. The gradient is calculated by comparing the result of previous calculation and last calculation and the zero when the value is the same. By using the same principal, this can be applied for more than one variable in local optimization as shows by Fig.3. This combination is called Global and Local Optimization (GOLOC).

\section{Discussion}

\subsection{Global Optimum}

The global optimization using ANN method is constructed in Visual Basic-Excel. VBA has the function of variable variation which has been defined, looping calculation was conducted to obtain results in each combination of the variable variation. Ms. Excel was functioned as the tool to calculate the technical and economical requirements of the vessel. VBA program is embedded in Ms. Excel.

The variable variation which has been conducted resulted four main particulars of vessel. The variable variations are: $2,4,6,8$, and 10 . The number of variation and its interval is in the same distance, since there are four main particulars, then it resulted combination which follows 2 variable variations $=16$ combinations or training. In the next combination resulted 256, 1298, 4069 and 10000 . All training is failed, only 10000 training result 14 objective function which fulfilled all constrains is shown in Table 1 
Table 1: Global Optimization Result

\begin{tabular}{|c|c|c|c|c|c|c|c|c|}
\hline \multirow{3}{*}{$\begin{array}{l}\text { Objective } \\
\text { Function (x } \\
\left.\text { Rp. } 10^{9}\right)\end{array}$} & \multicolumn{8}{|c|}{ Required Variables Combination } \\
\hline & 1 & 2 & 3 & 4 & 5 & 6 & 7 & 8 \\
\hline & 15.75 & 16.00 & 15.67 & 16.23 & 15.86 & 16.25 & 16.46 & 15.83 \\
\hline \multirow{2}{*}{$\begin{array}{l}\text { Objective } \\
\text { Function (x } \\
\left.\text { Rp. } 10^{9}\right)\end{array}$} & 9 & 10 & 11 & 12 & 13 & 14 & 15 & 16 \\
\hline & 16.64 & 16.28 & 16.78 & 16.38 & 16.67 & 16.28 & 16.34 & 16.85 \\
\hline
\end{tabular}

It shows that 16 combinations satisfy all constraints and Objective Function of each combination are obtained. The maximum Objective Function is $\mathrm{Rp} 16.85 \times 109$ and the minimum Objective Function is $\mathrm{Rp} 15.67 \times 109$. The difference between maximum and minimum Objective Function is Rp $1.18 \times 109$ or $7.02 \%$. The Objective Function of this calculation is to define the minimum cost, so the chosen result of global optimization is option No 1 (2nd Column).

conducted in the same distance based on the distance of upper limit and lower limit divided by variable variation. The modelling constructed in Visual Basic (VBA) of Ms Excel.

The local optimization or GRG is conducted in Ms. Excel. This optimization process is processed by using

\subsection{Local Optimum}

The local optimum solution was conducted using Nonlinear Generalized Reduced Gradient (GRG) which provided in Ms Excel. Nonlinear method was chosen due to the complex variables and includes nonlinear calculation. This method uses principal particulars variation which changed automatically, the change is moving to small gradient of Objective Function. The calculation precision was made to small (10-7) where the results is more accurate, the iteration is set to 1000 to obtain optimum results. The initial value in this calculation is very crucial since the mistake in the initial value will cause the failure in the calculation. Generally, the initial value was set by trial and error. Since the principal particulars of the vessel has fulfilled the constraint as shown by Table 1, so the value will be used as input in next calculation where the results is shown in Table 2.

Table 2: Local Optimization Result

\begin{tabular}{|c|c|c|c|c|c|c|c|c|}
\hline \multirow{3}{*}{$\begin{array}{c}\text { Objective } \\
\text { Function (x } \\
\left.\text { Rp. } 10^{9}\right)\end{array}$} & \multicolumn{8}{|c|}{ Required Variables Combination } \\
\hline & 1 & 2 & 3 & 4 & 5 & 6 & 7 & 8 \\
\hline & 15.63 & 15.88 & 15.66 & 16.09 & 15.85 & 16.11 & 16.66 & 15.33 \\
\hline \multirow{2}{*}{$\begin{array}{l}\text { Objective } \\
\text { Function }(\mathrm{x} \\
\left.\text { Rp. } 10^{9}\right)\end{array}$} & 9 & 10 & 11 & 12 & 13 & 14 & 15 & 16 \\
\hline & 16.71 & 16.35 & 16.81 & 16.26 & 16.56 & 15.91 & 16.34 & 16.84 \\
\hline
\end{tabular}

Table 2 shows the combination of principal particulars which satisfies all constraints. The values of principal particulars and Objective Function change to smaller value. The maximum Objective Function value is $\mathrm{Rp} 16.84 \times 10^{9}$ dan the minimum cost of value is $\mathrm{Rp} 15.33 \times 10^{9}$. The difference of maximum Objective Function and minium Objective Function is Rp $1.51 \times 10^{9}$ or $9.00 \%$. The gap of maximum and minimum values for local and global optimization becomes wider. The Objective Function in this calculation is to minimize the cost so the chosen of local optimization is alternative no.1 (Column 2). 


\subsection{GOLOC Optimum}

To simplify the analysis, the results of table 1 and 2 can be converted into Figure 3.

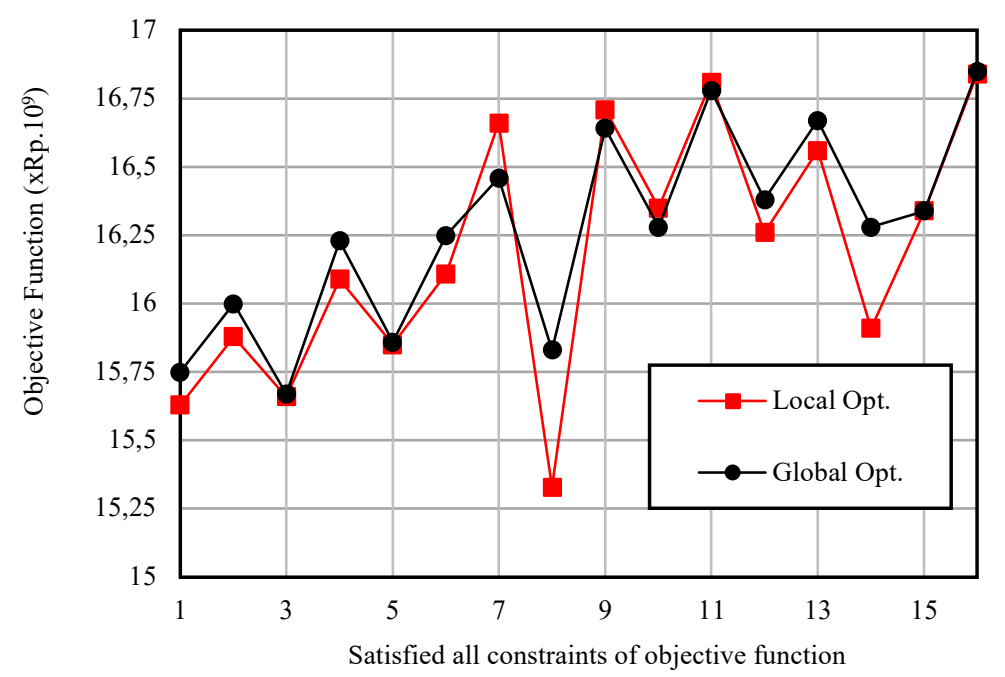

Figure 4: Comparison Graph of Global and Local Optimization.

Fig.4 is a comparison of global and local optimization based on Table I and II. The $\mathrm{x}$ axis represents 16 objective functions which satisfy constraints and $\mathrm{Y}$ axis is the value of the Objective Function. The black circle marker shows the global optimization and the red rectangle marker shows the local optimization. The process stared by global optimization and continued in local optimization. Generally, the local optimization results are lower compared to the global results. The result of global optimization which has higher values compared to local are achieved in Objective Function: 7, 9, 10 and 11. This difference of global shows by the Fig. 4 means that the global optimization is still can be optimized using local optimization. It also shows that global optimization or local optimization can be trapped in certain values which actually still can be optimized. The results of global optimization are calculated in local optimization will resulted in difference values or in this case is lower values. This evidence shows that local optimization is trapped in its locality, it is unable to move to other values. From the results of the optimization, if any initial values are calculated in the local optimization, the results show that most of the values are not satisfies all constraints. The global and local optimization is a combination which completing each other in order to accelerate the process of optimum results. 
Table 3: GOLOC Optimization Result

\begin{tabular}{|c|c|c|c|c|c|}
\hline Item & Unit & Symbol & $\begin{array}{l}\text { Constr } \\
\text { Min. } \\
\end{array}$ & $\begin{array}{c}\text { Optimum } \\
\text { Variable } \\
\end{array}$ & Constr Max \\
\hline \multicolumn{6}{|c|}{ Variables } \\
\hline Length of ship & $\mathrm{M}$ & $\mathrm{L}$ & 52.000 & 52.800 & 60.000 \\
\hline Width of ship & $\mathrm{m}$ & B & 10.000 & 11.809 & 13.000 \\
\hline Height of ship & $\mathrm{m}$ & $\mathrm{H}$ & 3.000 & 4.795 & 5.000 \\
\hline Draft of the ship & $\mathrm{m}$ & $\mathrm{T}$ & 1.820 & 2.285 & 3.000 \\
\hline \multicolumn{6}{|l|}{ Constraints } \\
\hline Margin (Disp.-LWT) & ton & Margin & -295.822 & -2409.599 & 2366.576 \\
\hline Deck Area Passenger & $\mathrm{m}^{2}$ & & 576.000 & 594.180 & 864.000 \\
\hline Deck Area Vehicle & $\mathrm{m}^{2}$ & & 480.557 & 594.180 & 1201.392 \\
\hline Gross Tonnage & $\mathrm{m}$ & GT & 590.000 & 951.510 & 1000.000 \\
\hline Freeboard & $\mathrm{cm}$ & $\mathrm{Fb}$ & 78.721 & 251.000 & 314.886 \\
\hline Initial GMo & $\mathrm{m}$ & GMo & 0.225 & 1.916 & 6.000 \\
\hline Area 0 to 30 & m.deg & $\mathrm{A}_{0 \sim 30}$ & 0.300 & 0.559 & 4.000 \\
\hline Area 0 to 40 & m.deg & $\mathrm{A}_{0 \sim 40}$ & 0.090 & 0.099 & 0.500 \\
\hline Area 30 to 40 & m.deg & $\mathrm{A}_{30 \sim 40}$ & 0.068 & 0.080 & 0.400 \\
\hline Max GZ at 30 or greater & $\mathrm{m}$ & $\mathrm{GZ}_{\max }$ & 25.000 & 25.912 & 50.000 \\
\hline Rolling period & Second & $\mathrm{T}$ & 4.400 & 5.152 & 13.000 \\
\hline \multicolumn{6}{|l|}{ Objective Function } \\
\hline Minimum Building Cost & $\mathrm{Rp}$ & \multicolumn{4}{|c|}{$15,327,363,905 .-$} \\
\hline
\end{tabular}

In the global optimization, the number of combination increases depend to the variation, the more variation will be resulted to more variables combination of principal particular which satisfies the constraints. The results of global optimization are still can be optimized using local optimization. But since the initial value determination in complex calculation is very difficult, the combination of global and local optimization can be used. The method will be a robust solution, the minimum Objective Function of global optimization is $\mathrm{Rp} 15.87 \times 10^{9}$ compared to minimum Objective Function of GOLOC is $\mathrm{Rp} 1.533 \times 10^{9}$, the difference is $\mathrm{Rp} 0.34 \times 10^{9}$ or $2.17 \%$. Maximum Objective Function of

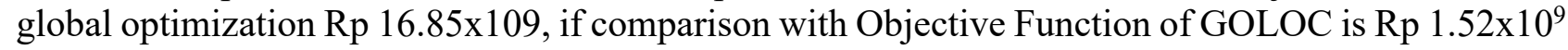
or $9.00 \%$.

Optimum GOLOC optimization can be shown on Table 3. The variables optimal of main ship particulars are: $\mathrm{L}=52.800 \mathrm{~m}, \mathrm{~B}=11.809 \mathrm{~m}, \mathrm{H}=4.795 \mathrm{~m}$, and $\mathrm{T}=2.285 \mathrm{~m}$. All constraints: Margin (Disp.-LWT), deck area passenger, deck area vehicle, gross tonnage, freeboard, and stability are fulfill requirements and regulations. The optimum Objective Function at minimum ship building is Rp. $15,327,363,905$

\subsection{General Arrangement}

General arrangement of the RoRo Passenger Vessel can be designed as the results of GOLOC optimization. Layout of the general arrangement is shown at Figure 5 there are four decks: car deck, intermediate deck, VVIP passenger deck and navigation deck. Car deck can carry: trailer, truck, APV, private car and motor cycle. On the left and right car deck, there are economy class passenger room and crew room. Intermediate deck position on the economy passenger room, in this room VIP passenger sit down on the chair. VVIP passenger deck location above intermediate deck. Behind VVIP passenger there are crew's room and safety equipment to abandon of the ship when danger situation occurred. Above VVIP deck, there is a navigation deck to control ship operation. Behind the navigation room there are officer's room. Chief officer on the left and chief engineer on the right. 

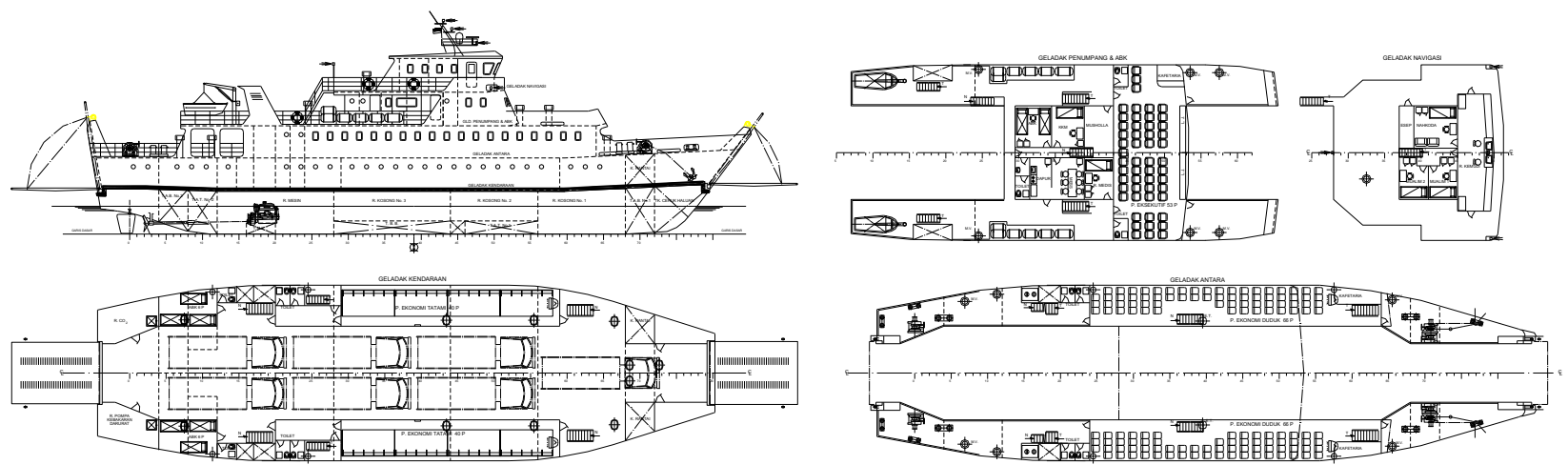

Figure 5: General Arrangement of RoRo Passenger Vessel.

\section{Conclusion}

Based on the GOLOC optimization method of RoPax, it can be concluded these several conclusions:

- Global optimization in this paper is using ANN, the ANN is simple to program and accurate. This global optimization outcome is a set principal particulars which fulfil constraints. But it can't get the best optimum of Objective Function.

- For Local optimization, this paper use GRG. The method is quick and accurate in obtaining the local maximum point. This result can be trapped in the set point or values as explained before.

- GOLOC is the best optimization because can close weakness both of global and local optimization. The procedure to use GOLOC, the first calculation global optimization, the second variables result used to input local optimization.

- In this paper, there are 17 results of global optimization which satisfies all required constraints which 10,000 training. The difference between maximum and minimum of global optimization result is $7.02 \%$. And the difference between minimum of global optimization and minimum of local optimization result is $2.17 \%$.

\section{References}

[1] J. Marshall, The Guinness Railway Book. Guinness Books, 1989

[2] A. Embankment, "IMO and Ro-Ro Safety," London SE1 7SR, United Kingdom, 1997.

[3] A. Papanikolaou, Ship Design: Methodologies Of Preliminary Design. Springer, 2014.

[4] M. Diez and D. Peri, "Robust optimization for ship conceptual design,” Ocean Eng., vol. 37, no. 11, pp. 966-977, Aug. 2010.

[5] K. Kazerounian and Z. Wang, "Global Versus Local Optimization in Redundancy Resolution of Robotic Manipulators,” Int. J. Robot. Res., vol. 7, no. 5, pp. 3-12, 1988.

[6] Z. Zhou, Y. S. Ong, P. B. Nair, A. J. Keane, and K. Y. Lum, "Combining Global and Local Surrogate Models To Accelerate Evolutionary Optimization,” IEEE Trans. Syst. Man Cybern. Part C Appl. Rev., vol. 37, no. 1, pp. 6676, 2007.

[7] K. B. Artana and K. Ishida, "Spreadsheet Modeling To Determine Optimum Ship Main Particulars and Power Requirements At Basic Design Stage,” Mar. Technol., vol. 40, no. 1, pp. 61-70, 2003.

[8] S. Percival, D. Hendrix, and F. Noblesse, "Hydrodynamic Optimization of Ship Hull Forms, "Appl. Ocean Res., vol. 23, no. 6, pp. 337-355, 2001.

[9] Y.-D. Liu and G. Bian, "Structure Topology Optimization and Second Development Based on ANSYS," J. Ship Mech., vol. 10, no. 2, p. 120, 2006.

[10] T. Ray, R. P. Gokarn, and O. P. Sha, “A Global Optimization Model for Ship Design,” Comput. Ind., vol. 26, no. 2, pp. 175-192, 1995.

[11] J. S. Rao, “Optimization,” in History of rotating machinery dynamics, Springer, 2011, pp. 341-351.

[12] R. Taggart, "Ship Design and Construction”. Society of Naval Architects \& Marine Engineers, 1980. 
[13] A. Papanikolaou, Ship Design: Methodologies of Preliminary Design. Springer, 2014.

[14] M. G. Parsons, "Parametric Design Chapter 11 in Ship Design and Construction," N. Y. Soc. Nav. Archit. Mar. Eng., 2003.

[15] J. Holtrop and G. G. Mennen, “An Approximate Power Prediction Method,” 1982.

[16] G. C. Manning, "The Theory And Technique Of Ship Design”. Technol. Press of the Massachusetts Inst. of Technology, 1956.

[17] IMO, “Intact Stability”. London, 2002.

[18] IMO, "International Convention on Load Lines". London, 2008.

[19] IMO, "International Convention on Tonnage Measurement of Ships". London, 1969.

[20] V. Bertram and H. Schneekluth, "Ship Design for Efficiency and Economy”. Butterworth-Heinemann, 1998. 